Received: 2016.11 .30

Accepted: 2017.01 .19

Published: 2017.09.15

\title{
Diffusion-Weighted Imaging and Color Doppler Ultrasound in Evaluation of Partial Testicular Torsion in Rat Model
}

Authors' Contribution:
A Study Design
B Data Collection
C Statistical Analysis
D Data Interpretation
E Manuscript Preparation
F Literature Search
G Funds Collection

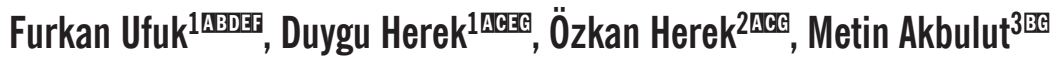

1 Department of Radiology, University of Pamukkale, Denizli, Turkey

2 Department of Pediatric Surgery, University of Pamukkale, Denizli, Turkey

3 Department of Pathology, University of Pamukkale, Denizli, Turkey

Author's address: Furkan Ufuk, Department of Radiology, University of Pamukkale, Denizli, Turkey, e-mail: furkan.ufuk@hotmail.com

Results: In the torsion group, minimum $\mathrm{ADC}$ values for left testicles were significantly lower than for the control group $(\mathrm{p}<0.05)$, regardless of the observer. Inter-observer agreement for measurements of $\mathrm{ADCmin}$ and $\mathrm{ADCmax}$ values was substantial, with an ICC score of 0.751 and 0.774 , respectively (95\% CI). Inter-observer agreement for the measurement of ADCmean value was excellent, with an ICC score of 0.844 (95\% CI). The pathological examination revealed mild interstitial edema and closely packed seminiferous tubules in the left testes, indicating reversible damage in the torsion group.

Conclusions: $\quad$ On the pathological examination, all left testes in the torsion group were recoverable after four hours of torsion. Minimum ADC values can be used as an auxiliary method in the diagnosis of partial testicular torsion. Comparing minimum ADC values between the affected and non-affected testicles can be a useful tool in the early diagnosis of incomplete testicular torsion.

MeSH Keywords:

Diagnosis • Diffusion Magnetic Resonance Imaging • Infertility • Spermatic Cord Torsion • Ultrasonography, Doppler, Color

PDF file: $\quad$ http://www.polradiol.com/abstract/index/idArt/902613

\section{Background}

Testicular torsion (TT) occurs due to twisting of the spermatic cord, and rapid diagnosis and subsequent treatment are necessary. Delay in the diagnosis may cause loss of gonad and infertility [1]. Color Doppler ultrasound (CDUS) is the first-line imaging method that provides the best results in the diagnosis of complete TT. Partial or incomplete TT is due to twisting of the spermatic cord by $360^{\circ}$ or less, and it is difficult to diagnose by CDUS because of the 

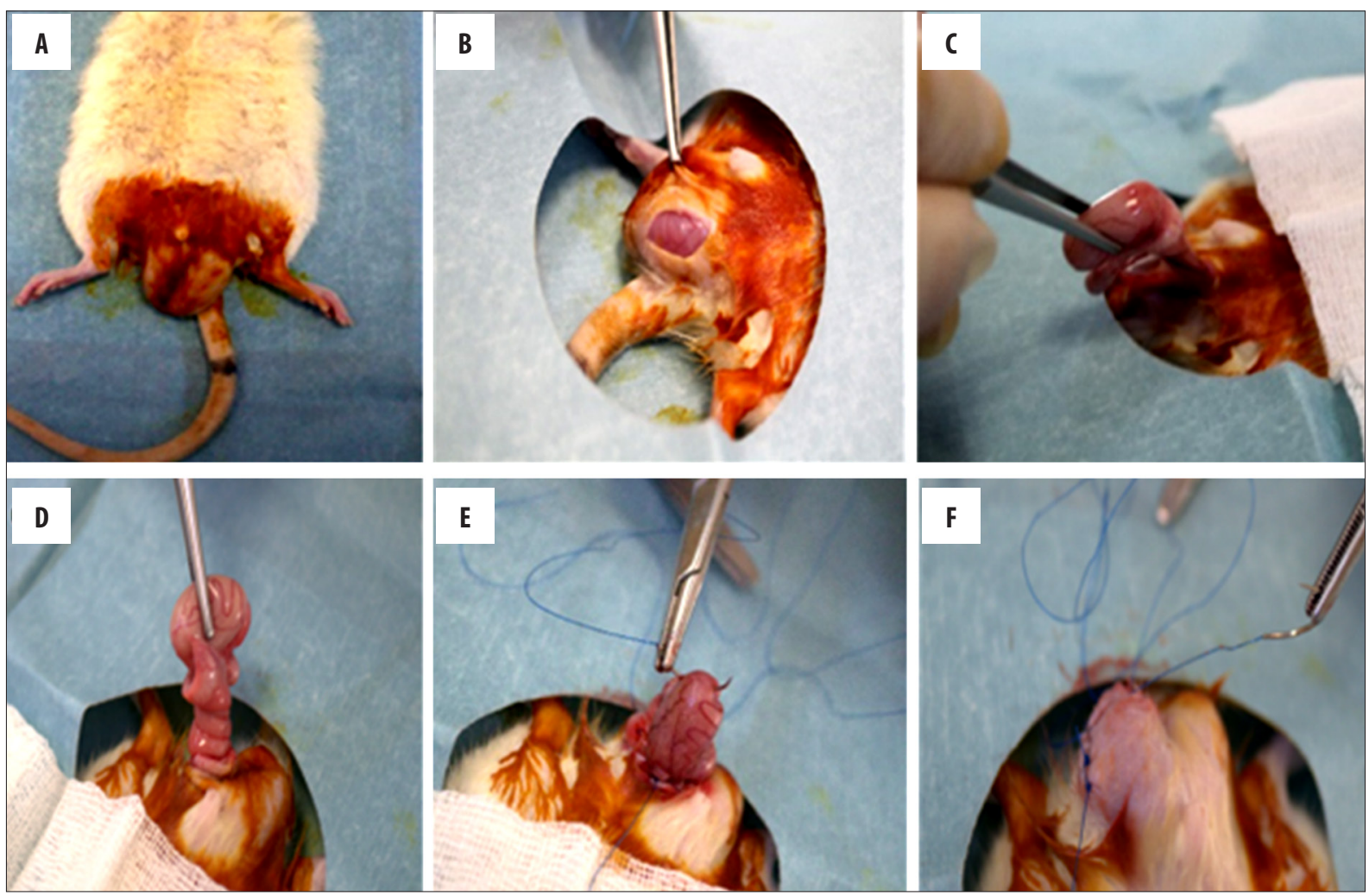

Figure 1. Surgical protocol. (A) Cleaning of the surgical site with povidone iodine, (B) scrotal left vertical incision, (C) taking the left testicle out, (D) creation of testicular torsion, left testicle is rotated clockwise by 1080 degrees, (E) fixing the testicle to the scrotal wall, (F) suturing the scrotal incision.

presence of blood flow. Subtle decreases in testicular blood flow are often difficult to detect on CDUS. There is a high false-negative rate for the diagnosis of incomplete TT on CDUS [2-4]. Therefore, additional methods are needed to support the diagnosis.

Measurement of the apparent diffusion coefficient (ADC) with diffusion-weighted imaging (DWI) is an expensive and time-consuming magnetic resonance imaging (MRI) sequence. It has been shown to be successful in the diagnosis of complete TT [5]. However, to the best of our knowledge, correlation between DWI and a histopathological examination of partial TT in an early period has not been investigated to date. The aim of this study was to evaluate the utility of DWI with histogram analysis of $\mathrm{ADC}$ in the diagnosis of incomplete TT.

\section{Material and Methods}

\section{Study population and surgical procedures}

Our study was approved by the Local Institutional Ethics Committee on Animal Care and Use (Pamukkale University, Animal Research and Ethics Committee, Decision number: 01, Date: 14.01.2014). Fourteen male Wistar albino rats, 3-4 months old and weighing 350-400 grams, were used in this experimental study. The rats were allocated randomly into two groups (seven rats per group). The animals were anesthetized by an intramuscular injection of $50 \mathrm{mg} /$ $\mathrm{kg}$ ketamine and $10 \mathrm{mg} / \mathrm{kg}$ xylazine hydrochloride before surgical procedures and MRI examinations. For all surgical procedures, under standard sterile conditions, a vertical scrotal incision was performed to access the left testicle. In group 1 (control group), the left testicle was kept outside for 45 seconds and then replaced. Left testicles were twisted by 360 degrees in group 2 (torsion group). In group 2, the left testicles were fixed with sutures to the scrotum from their upper and lower poles, avoiding vascular structures, to prevent spontaneous detorsion. Scrotum was closed with sutures in all rats (Figure 1). The occurrence of testicular damage during surgery resulted in exclusion from the study. After surgery, the rats were stabilized on a carriage board after four hours, and underwent an MRI examination. After MRI, testicular color Doppler ultrasound was performed.

\section{Magnetic resonance imaging}

All MRI examinations were performed with a 1.5 Tesla MRI system (Ingenia; Philips Medical Systems, Best, The Netherlands) with a 16-channel head coil and high performance gradient (maximum gradient, $45 \mathrm{mT} / \mathrm{m}$; maximum slew rate, $200 \mathrm{~T} / \mathrm{m} / \mathrm{s})$. Axial, DWI, Single Shot Echo Planar Imaging sequence with sensitivity encoding (SENSE) (4000/90; matrix size, $62 \times 112$; slice thickness, $3 \mathrm{~mm}$; interslice gap, 10\%; field of view, $45 \mathrm{~cm}^{2}$; number of signals averaged, 6; acquisition time, 1 minutes 56 seconds) was performed with $b$ values of 0 and $800 \mathrm{sec} / \mathrm{mm}^{2}$. Two radiologists, one with 10 years of experience and the other with 5 years of experience in MRI, reviewed the images. ADC values of each testicle were measured three times by placing at least three ellipsoid regions-of-interests (ROIs) 


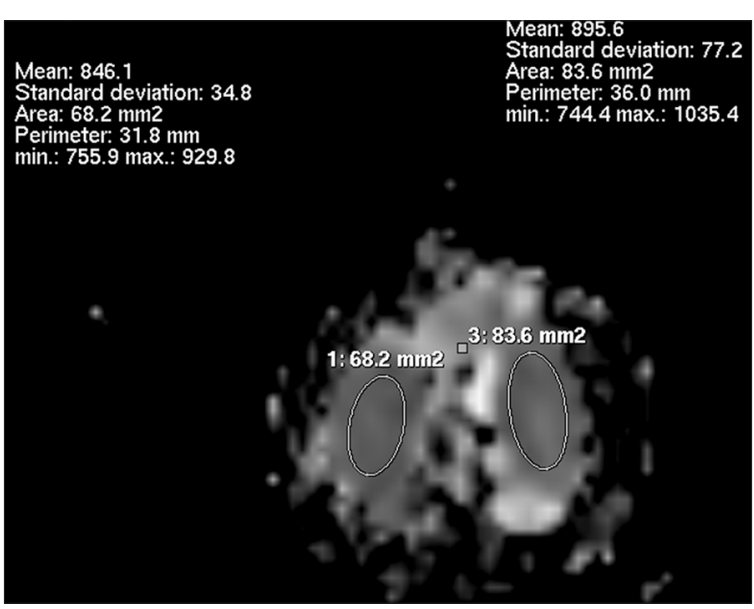

Figure 2. Axial $A D C$ measurement in group 2 (torsion group) testicles on $A D C$ map images.

in the middle portions of testicles in the ADC map images by two radiologists who were blinded to each other's measurements. ADC values were calculated on a pixel-by-pixel basis for histogram analysis. Ellipsoid ROIs were placed in order to cover the entire testicular parenchyma that was free of artifacts (Figure 2).

\section{Ultrasound examinations}

Color Doppler ultrasound examinations were performed with a sonographic scanner (LOGIQ E9, GE, Healthcare, Milwaukee, WI, USA) with an 11-15 $\mathrm{MHz}$ linear probe. Two radiologists reviewed the images of all testes together, objectively, for the presence or absence of blood flow.

\section{Pathologic evaluation}

All the left testes in group 2 were surgically removed after four hours of torsion. Testicular tissue samples were fixed and embedded in paraffin. 5- $\mu$ tissue sections were cut from each slice, glass-mounted, and stained with hematoxylin and eosin (HEE). All slices were evaluated under the light microscope by a pathologist with 15 years of experience who was blinded to all procedures.

\section{Statistical analysis}

Statistical analyses were performed with SPSS, version 21 (SPSS for Windows, release 21.0; SPSS, Chicago, IL, USA). Quantitative variables were expressed as minimum, maximum, and mean \pm standard deviation (SD). Intergroup and inter-site comparisons were performed using the Wilcoxon test. $P$ value of 0.05 or less was considered as statistically significant. An inter-observer reliability analysis with the Kappa statistic was performed to determine consistency among raters. Intraclass correlation coefficient (ICC) scores with 95\% CIs were calculated. Inter-observer agreement was categorized as follows: $0-0.20$, poor; $0.21-0.39$, fair; 0.40-0.59, moderate; 0.60-0.79, substantial; and 0.80-1.00, almost perfect.

\section{Results}

We found a statistically significant difference in the minimum ADC (ADCmin) values of the left testicles between torsion and control groups $(\mathrm{p}<0.05)$, for both radiologists (Table 1). Inter-observer agreement for the measurement of ADCmin value was substantial, with an ICC score of 0.751 (95\% CI). There were no significant differences in the mean $\mathrm{ADC}$ (ADCmean) and maximum ADC (ADCmax) values of the twisted testicles, as compared with the control group, for both radiologists. The measurements of ADCmean and ADCmax values between radiologist 1 and 2 , in control and torsion groups, were not significantly different $(\mathrm{p}>0.05)$ (Table 1). Inter-observer agreement for the measurement of ADCmax value was again substantial, with an ICC score of $0.774(95 \% \mathrm{CI})$. Inter-observer agreement for the measurement of ADCmean value was excellent, with an ICC score of $0.844(95 \% \mathrm{CI})$. The average ROI size was $72 \mathrm{~mm}^{2}$ $\left(62-98 \mathrm{~mm}^{2}\right)$, and there were no significant differences in the average ROI sizes between the groups.

Color Doppler US objectively showed blood flow in all testicles in group 1 and group 2 (Figure 3).

The pathological examination revealed mild interstitial edema and closely packed seminiferous tubules in the left testes, indicating reversible damage in the torsion group (Figure 4). In the control group, all testes were histopathologically normal,.

Table 1. Comparison of left testicle minimum, mean and maximum ADC values in group 1 (control group) and group 2 (torsion group) for each radiologist.

\begin{tabular}{lcccccc}
\hline & \multicolumn{3}{c}{ Radiologist 1 } & & \multicolumn{2}{c}{ Radiologist 2 } \\
\cline { 2 - 7 } & $\begin{array}{c}\text { Group 1 } \\
\text { (Control) }\end{array}$ & $\begin{array}{c}\text { Group 2 } \\
\text { (Torsion) }\end{array}$ & $p$ Value & $\begin{array}{c}\text { Group 1 } \\
\text { (Control) }\end{array}$ & $\begin{array}{c}\text { Group 2 } \\
\text { (Torsion) }\end{array}$ & $p$ Value \\
\hline $\begin{array}{l}\mathrm{ADCmin} \\
\left(10^{-3} \mathrm{~mm}^{2} / \mathrm{sn}\right)\end{array}$ & $0.721 \pm 13$ & $0.688 \pm 19$ & 0.01 & $0.716 \pm 23$ & $0.686 \pm 17$ & 0.01 \\
\hline $\begin{array}{l}\mathrm{ADCmean} \\
\left(10^{-3} \mathrm{~mm}^{2} / \mathrm{sn}\right)\end{array}$ & $0.774 \pm 17$ & $0.763 \pm 14$ & 0.133 & $0.754 \pm 9$ & $0.766 \pm 22$ & 0.064 \\
\hline $\begin{array}{l}\mathrm{ADCmax} \\
\left(10^{-3} \mathrm{~mm}^{2} / \mathrm{sn}\right)\end{array}$ & $0.863 \pm 22$ & $0.852 \pm 24$ & 0.538 & $0.859 \pm 19$ & $0.855 \pm 18$ & 0.787 \\
\hline
\end{tabular}

Data are presented as mean \pm standard deviation. $A D C$ min - minimum $A D C ; A D C$ max - maximum ADC; Std. - standard deviation. 


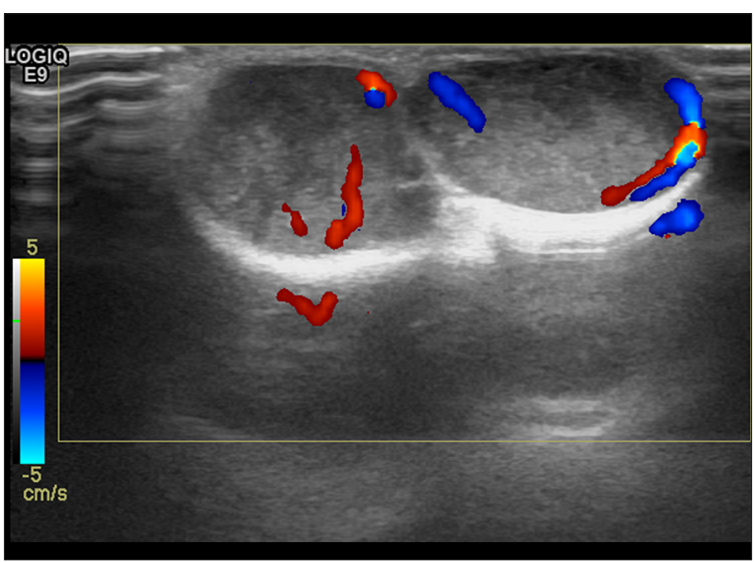

Figure 3. Color Doppler US image shows bilateral blood flow in testicles in group 2 (torsion group).

\section{Discussion}

In incomplete testicular torsion, blood flow can be seen in testicular tissue, which can be confusing. A decrease in testicular blood flow may be detected in the early period on CDUS, subjectively. In this study, we aimed to evaluate the utility of DWI with histogram analysis of ADC in the diagnosis of incomplete TT and show whether DWI would help in the diagnosis.

This study demonstrated that $\mathrm{ADCmin}$ values may help in the diagnosis of incomplete TT. The mean and maximum $\mathrm{ADC}$ values are ineffective in the diagnosis of incomplete TT after four hours of torsion. All the left testes in the torsion group were recoverable.

There are two peak ages in patients with testicular torsion; in the newborn period and around 13 years of age, respectively [6]. Therefore, pubertal rats were used in our study. In addition, because of the long spermatic cords, testicular torsion is seen twice as often on the left than on the right [7]. Therefore, we thought that investigating left testicular torsion would be more appropriate for translation of the results in the clinical setting. In experimental studies, ischemia in the testis is induced by twisting the testis and spermatic cords together, by clamping or ligation of the testicular artery [8]. Palmer et al. [9] showed that injury of the seminiferous tubules in the model created by clamping testicular artery is not compatible with the testicular torsion that is observed in clinical cases. Therefore, in accordance with that fact, we chose to induce testicular torsion by twisting the testicles in the clockwise direction.

Color Doppler ultrasound is an easily accessible, cheap, and non-invasive diagnostic method which is used as the first-line study in patients with scrotal pain. Diagnosis of TT by CDUS also depends on user's experience, knowledge, and device quality, which is disadvantageous, especially in the diagnosis of incomplete torsion. In incomplete torsion, blood flow can be seen in testicular tissue, as it was seen in the testicles in our study, which might lead to false negative results [10-12]. Presence of blood flow on CDUS does not exclude a diagnosis of partial torsion, as seen in our study. A decrease in testicular blood flow may be detected in the early period on CDUS, subjectively. In the case

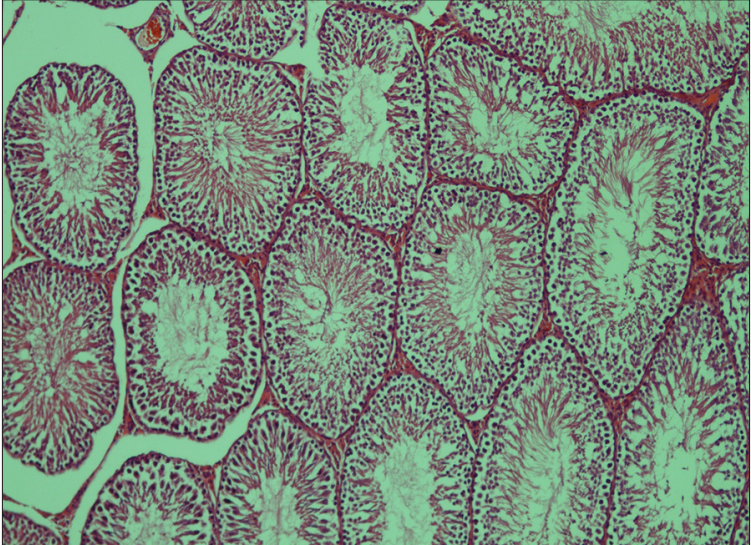

Figure 4. Rat with a $360^{\circ}$ testicular torsion (group 2).

Photomicrograph of a histologic specimen shows closely packed seminiferous tubules and mild interstitial edema (hematoxylin and eosin stain, $\times 20$ ).

of partial torsion, blood flow on CDUS decreases initially, while in the later period it may be undetectable due to increased interstitial pressure [13].

Diffusion weighted imaging (DWI), that measures the microscopic movements of water molecules, is an MRI sequence that does not require injection of contrast material $[14,15]$. However, it generates higher costs than sonographic evaluations, is not easily accessible, the image quality is low, and it is difficult to perform in childhood because of the need for anesthesia to keep the child immobile during the examination $[16,17]$. For these reasons, it has limited use. Diffusion weighted imaging has been shown to be a successful method in the diagnosis of complete TT in the early period $[5,18]$. However, to the best of our knowledge, the role of DWI in partial testicular torsion in the early stage has not been investigated to date. In our study, we compared mean and maximum ADC values of left testes between the groups after four hours of torsion; we observed slightly but not significantly decreased ADC values in the torsion group in comparison to the control group, which may support the presence of mild ischemic changes. Minimum ADC values of the torsion group were significantly lower than those found in the control group. Based on these data, a reduction of the ADCmin value is seen in the early period of testicular torsion on DWI. We suggest that ADCmin values begin to decrease in the affected testicle due to early cellular ischemia, but meanwhile, no significant change is observed in the $\mathrm{ADCmean}$ and $\mathrm{ADCmax}$ values, consistent with previous results [19]. Later, ADCmean and $\mathrm{ADCmax}$ values may also decrease significantly due to widespread cellular ischemia. However, larger studies are required to confirm that. We suggest that DWI with the measurement of minimum ADC values can be used as an auxiliary method in suspected cases of partial testicular torsion. ADCmin values may be suggestive of testicular torsion, when CDU is normal in partial testicular torsion.

In our study, inter-observer agreement for the measurements of ADCmin and ADCmax values was substantial, and for the measurement of ADCmean value it was excellent. This indicates that the measurement of ADCmean values is less observer-dependent than the measurement of $\mathrm{ADCmin}$ 
and $\mathrm{ADCmax}$ values. We suggest that this is due to the fact that $\mathrm{ADCmin}$ and $\mathrm{ADCmax}$ values are only single numbers and easily change in different measurements. However, the $\mathrm{ADCmean}$ value is an arithmetic mean and does not change easily.

Salvage rates are almost $100 \%$ if testicular blood flow is reestablished within 6 hours. However, it decreases to $70 \%$ between 6 and 12 hours, and to less than $10 \%$ after 24 hours [1]. On the histopathological examination, the $360^{\circ}$ TT testicles were $100 \%$ recoverable after four hours of torsion, consistent with previous results.

This study has some limitations. First, this is an experimental study and therefore it needs to be confirmed by clinical observations. Second, due to a small number of cases, non-parametric tests were used, and we were unable to identify a clear threshold value. Notably, in cases with bilateral simultaneous TT or in patients with single

\section{References:}

1. Turner TT, Brown KJ: Spermatic cord torsion: Loss of spermatogenesis despite return of blood flow. Biol Reprod, 1993; 49: 401-7

2. Fishman AJ, Ahmad M, Chheda $\mathrm{H}$ et al: Reliability of radionuclide scintigraphy for detection of testicular torsion: An animal study. Eur J Nucl Med, 1990; 16: 657-61

3. Atkinson GO, Patrick LE, Ball TI et al: The normal and abnormal scrotum in children: Evaluation with color Doppler sonography. Am J Roentgenol, 1992; 158: 617-18

4. Sanelli PC, Burke BJ, Lee L: Color and spectral Doppler sonography of partial torsion of the spermatic cord. Am J Roentgenol, 1999; 172(1): 49-51

5. Kangasniemi M, Kaipia A, Joensuu R: Diffusion weighted magnetic resonance imaging of rat testes: A method for early detection of ischemia. J Urol, 2001; 166: 2542-44

6. Bartsch G, Frank S, Marberger H, Mikuz G: Testicular torsion: Late results withspecial to fertility and endocrine function. J Urol, 1980 124: $375-77$

7. Fonkalsrud EW: Testicular undescent and torsion. Pediatr Clin North Am, 1987; 34: 1305-17

8. Bergh A, Damber JE, Marklund SL: Morphologic changes induced by short-term ischemia in the rat testis are not affected by treatment with superoxide dismutase and catalase. J Androl, 1988; 9: 15-20

9. Palmer JS, Plzak LF, Cromie WJ: Comparison of blood flow and histological changes in rat models of testicular ischemia. J Urol, 1997; 158: 1138-40 testicles, comparison of ADC values between testicles is not possible. Third, color Doppler ultrasound images were evaluated by two radiologists together and therefore interobserver variability could not be assessed.

\section{Conclusions}

In conclusion, even a negative CDUS would not preclude the presence of a partial torsion. In case of doubt, DWI can be used as an auxiliary method in the diagnosis of partial testicular torsion. Comparing minimum $\mathrm{ADC}$ values between the affected and non-affected testicles can be useful in the early diagnosis of incomplete testicular torsion. Testes with $360^{\circ}$ torsion were recoverable after four hours of torsion.

\section{Conflict of interest}

The authors declare that they have no conflict of interest.

10. Yagil Y, Naroditsky I, Milhem J et al: Role of Doppler ultrasonography in the triage of acute scrotum in the emergency department. J Ultrasound Med, 2010; 29: 11-21

11. Kühn AL, Scortegagna E, Nowitzki KM, Kim YH: Ultrasonography of the scrotum in adults. Ultrasonography, 2016; 35: 180-97

12. Bhatt S, Dogra VS: Role of US in testicular and scrotal trauma. Radiographics, 2008; 28: 1617-29

13. Patriquin HB, Yazbeck S, Trinh B et al: Testicular torsion in infants and children: Diagnosis with Doppler sonography. Radiology, 1993; 188: 781-85

14. Bammer R: Basic principles of diffusion-weighted imaging. Eur $\mathrm{J}$ Radiol, 2003; 45: 169-84

15. Qayyum A: Diffusion-weighted imaging in the abdomen and pelvis: Concepts and applications. Radiographics, 2009; 2: 1797-810

16. Maki D, Watanabe Y, Nagayama M et al: Diffusion-weighted magnetic resonance imaging in the detection of testicular torsion: Feasibility study. J Magn Reson Imaging, 2011; 34: 1137-42

17. Gotto GT, Chang SD, Nigro MK: MRI in the diagnosis of incomplete testicular torsion. Br J Radiol, 2010; 83: el05-7

18. Kaipia A, Ryymin P, Mäkelä E et al: Magnetic resonance imaging of experimental testicular torsion. Int J Androl, 2005; 28: 355-39

19. Ufuk F, Herek D, Herek Ö, Akbulut M: Role of diffusion weighted magnetic resonance imaging in a rat model of testicular torsion. Br J Radiol, 2016; 89(1068): 20160585 